\title{
Breve Histórico do Pensamento Psicológico Brasileiro Sobre Relações Étnico-Raciais
}

\author{
Brief History Of Brazilian Psychological \\ Thinking About Ethnic/Racial Relationships \\ Breve Histórico Del Pensamiento Psicológico \\ Brasileño Sobre Relaciones Étnico-Raciales
}

Alessandro de

Oliveira dos Santos Universidade de São Paulo

Lia Vainer Schucman Universidade de São Paulo

Hildeberto Vieira Martins

Universidade Federal Fluminense 
Resumo: $\mathrm{O}$ artigo descreve três momentos do pensamento psicológico brasileiro sobre relações étnicoraciais no final do século XIX e no início do século XX, caracterizado pela consolidação da Escola Nina Rodrigues, que investiga características psicológicas dos escravos e ex-escravos e fornece elementos para a configuração do negro como sujeito psicológico; o período de 1930 até 1950 é caracterizado pelo debate da construção sociocultural das diferenças e da desconstrução do determinismo biológico das raças, e o período de 1990 em diante, pelos estudos sobre branqueamento e branquitude. Utilizando a perspectiva histórica, foi possível traçar uma linha no tempo identificando esses momentos de ruptura e de configuração de novos saberes em Psicologia: biológico-causal, culturalista e relacional. A construção dessa linha no tempo configura uma tentativa de trazer para o campo da Psicologia uma outra perspectiva de discussão da temática étnico-racial, repensando o papel dos modelos e das teorias psicológicas.

Palavras-chave: História da Psicologia-Brasil. Relações étnico-raciais. Psicologia social. Atitudes étnicas e raciais.

Abstract: The article describes three periods of the Brazilian psychological thinking about ethnic/racial relationships: the late nineteenth and the early twentieth century, characterized by the consolidation of the Escola Nina Rodrigues, which investigated the psychological characteristics of slaves and former slaves, providing elements for setting the black as psychological subjects; from 1930 to 1950 the studies are characterized by the debate on the differences of social and cultural construction and deconstruction of biological determinism of race, and from 1990 onwards, characterized by the studies on "whitening" and "whiteness". Using the historical approach, it was possible to draw a timeline identifying these moments of rupture and configuration of new knowledge in psychology: biological-causal, cultural and relational. The construction of this timeline sets an attempt to bring to the field of psychology a different perspective of discussion about the ethnic/racial thematic, thinking over the role of psychological theories and models. Keywords: History of psychology-Brazil. Ethnic-racial relations. Social psychology. Racial ethinic attitudes.

Resumen: El artículo describe tres momentos del pensamiento psicológico brasileño sobre relaciones étnico-raciales en el final del siglo XIX y en el inicio del siglo XX, caracterizado por la consolidación de la Escuela Nina Rodrigues, que investiga características psicológicas de los esclavos y ex-esclavos y proporciona elementos para la configuración del negro como sujeto psicológico; el período de 1930 hasta 1950 es caracterizado por el debate de la construcción sociocultural de las diferencias y de la desconstrucción del determinismo biológico de las razas, y el período de 1990 en adelante, por los estudios sobre blanqueamiento y blancura. Utilizando la perspectiva histórica, fue posible trazar una línea en el tiempo identificando esos momentos de ruptura y de configuración de nuevos saberes en Psicología: biológico-causal, culturalista y relacional. La construcción de esa línea en el tiempo configura una tentativa de traer para el campo de la Psicología otra perspectiva de discusión de la temática étnico-racial, repensando el papel de los modelos y de las teorías psicológicas.

Palabras clave: Historia de la Psicología. Relaciones étnico-raciales. Psicología social. Actitudes étnicas o raciales.

Este artigo descreve o que aqui identificamos como três momentos do pensamento psicológico brasileiro acerca das relações étnico-raciais no País:

(a) Período do final do século XIX e início do XX - caracterizado pelo surgimento e consolidação de um modelo médicopsicológico que culminou na Escola Nina Rodrigues, que atribui e investiga as características psicológicas dos escravos e exescravos, a massa negra, considerada por uma parcela da sociedade brasileira um elemento perigoso, e, por isso, sujeito ao controle e à exclusão social. O olhar científico sobre esse grupo social fornece os elementos necessários para a configuração do negro como sujeito psicológico e objeto da ciência.

(b) Período de 1930 até 1950 - caracterizado pela introdução da Psicologia no ensino superior e pelo debate sobre a construção sociocultural das diferenças: contribuições de Raul Briquet, Arthur Ramos, Donald Pierson, Virginia Leone Bicudo, Aniela Ginsberg e Dante Moreira Leite. É um momento de crítica e de desconstrução do determinismo biológico das raças na constituição do campo da Psicologia e da Psicologia social no Brasil. (c) Período de 1990 em diante - caracterizado 


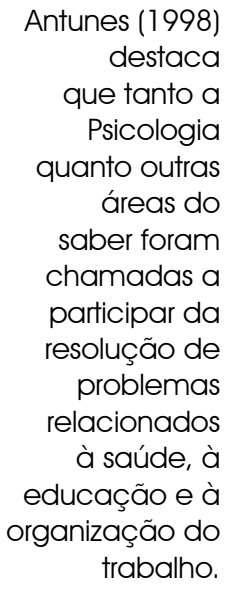

pelo início dos estudos em Psicologia sobre branqueamento e branquitude, com Jurandir Freire Costa, Irai Carone, Maria Aparecida Bento e Edith Pizza, e de debates e ações de promoção da igualdade étnico-racial no Brasil. Nesse momento, a discussão do legado social do branqueamento e de seus efeitos psicológicos sobre a identidade étnico/racial da pessoa negra é retomada de maneira crítica, ao mesmo tempo em que se reflete sobre a identidade étnico/racial da pessoa branca, denominada branquitude.

O artigo tem como meta contribuir para a ampliação do debate entre pesquisadores e psicólogos que, nas suas várias frentes de trabalho, têm sido interpelados pela problemática das relações étnico-raciais, e para aprofundar a reflexão sobre os discursos e as práticas da Psicologia ao longo de sua história quanto a essa questão.

\section{O surgimento da Psicologia no Brasil e a Escola Nina Rodrigues}

A constituição das relações interculturais e raciais no Brasil decorre de grandes fluxos migratórios ligados ao processo de colonização no século XVI, a Revolução Industrial, nos séculos XVIII e XIX, e as grandes guerras, no século XX.

No século XIX, o tema das relações étnicoraciais adquire importância capital para o Brasil, que começava a se tornar independente do jugo português. Quem são os cidadãos desse novo país? Para responder essa pergunta, tentar-se-á então construir uma imagem que coloque o Brasil no caminho das luzes e do progresso que a Europa já havia alcançado. Com a constituição de um novo contexto social e político, anuncia-se o empecilho e o paradoxo de lidar com a escravidão, e, ao mesmo tempo, com os ideais liberais. Afinal, como construir uma nação de iguais se a escravidão (desigualdade) persiste? Eis o problema do Brasil e dos seus intelectuais, como diz Schwarz (1995).

Durante o processo de transformação pelo qual passou o Brasil na virada do século XIX para o XX, problemas antigos se colocaram novamente no quadro de modernização e de nacionalização da identidade do povo brasileiro. De acordo com Massimi, o Brasil se encontrava, nesse período, "diante do desafio de tornar-se uma nação moderna tendo um projeto unitário político, social e cultural" (2007, p.159). A crescente atuação do Estado na gerência de diversos aspectos da vida cotidiana trouxe uma "progressiva estruturação dos papéis dos indivíduos, vindo estes a ser considerados como funções e produtos do processo social" (2007, p.159). Dessa forma, foram postos em marcha meios que permitissem consolidar, como instrumentos de promoção do processo de modernização, saberes que oferecessem uma leitura funcional da relação entre ser humano e sociedade.

Antunes (1998) destaca que tanto a Psicologia quanto outras áreas do saber foram chamadas a participar da resolução de problemas relacionados à saúde, à educação e à organização do trabalho. Nesse período, a Psicologia foi amplamente associada à Medicina e à educação. De acordo com a autora, grande parte dos trabalhos que versavam sobre assuntos psicológicos nessa época era fruto de teses nas áreas de psiquiatria, neurologia, Medicina social e Medicina legal, de alunos de faculdades de Medicina do Rio de Janeiro e da Bahia. Em diversos desses trabalhos, foram feitas associações entre características étnicoraciais e tipos de caráter, atribuindo-se certas formas de doença mental como típicas de determinadas etnias-raças. Tais trabalhos ganharam evidência no Brasil devido ao crescimento de uma imprensa nacional que fez dos jornais da época um dos espaços 
privilegiados para a apresentação e a difusão de ideias defendidas por médicos, cientistas, políticos e juristas.

No final do século XIX, a articulação entre raça e nação produzia seus primeiros efeitos com base em estudos acadêmicos sobre o negro e sobre a análise dos aspectos sociais, culturais e políticos decorrentes da presença desse grupo na sociedade brasileira. $\mathrm{O}$ problema de qual raça resultava ao final do processo de miscigenação (fenômeno social que foi considerado, em certos períodos, o problema e também a solução do Brasil) e de como esse problema afetava a sociedade brasileira estava presente nos discursos e nas práticas interessados em propor soluções às dificuldades de formação de uma sociedade civilizada.

É nesse momento que o médico Raimundo Nina Rodrigues afirma a importância da raça como fator explicativo fundamental da sociedade brasileira e de seus cidadãos. Com base no evolucionismo social ou darwinismo social, segundo o qual os seres humanos são desiguais por natureza devido às diferentes aptidões inatas que fazem de uns superiores e outros inferiores, ele produziu estudos relacionando raça, patologias psiquiátricas e tipologias criminais. E elaborou o conceito de que o retrocesso econômico da Bahia se devia à grande presença da raça negra e de mestiços no Estado, que, com suas doenças, costumes e religião, influenciavam o restante da população. Para ele, os mestiços não conformavam uma raça, mas eram inferiores pela influência de seus ancestrais negros e indígenas (Chaves, 2003). Trata-se de um discurso formulado a partir da constituição da ideia de degeneração da raça, que tem seu eixo central no problema negro, e à qual a nascente psiquiatria brasileira é chamada a responder, como divulgadora de uma ideia de raça e de nação a partir do modelo da Medicina legal.
Os trabalhos de Raimundo Nina Rodrigues e da denominada Escola Baiana de Antropologia ou Escola Nina Rodrigues possibilitaram a formulação de um modelo psicofísico de explicação sobre as deficiências do negro brasileiro e sobre as consequências sociais da manutenção do convívio com essa raça. Tal discussão teve continuidade no início do século XX pelas mãos de alguns dos seus discípulos, como Arthur Ramos, Juliano Moreira e Afrânio Peixoto (Martins, 2009).

A progressiva penetração das teorias científicas na cultura brasileira associou-se fortemente às formas de interpretação das relações étnico-raciais. Segundo Costa, a psiquiatria brasileira, a partir da década de 1930, passou a ter grande apreço pela "incidência e prevalência dos diversos tipos de doença mental e sua distribuição étnica" (2007, p.117). Nesse período, os negros e os mestiços recebiam muito mais diagnósticos de doenças mentais toxinfecciosas, como a sífilis e o alcoolismo, do que os brancos. E também eram mais acometidos pelas doenças chamadas constitucionais, como a esquizofrenia e a psicose maníaco-depressiva.

\section{Crítica e desconstrução do determinismo biológico das raças}

A partir da década de 30, o debate sobre raça e nação só se intensificaria no campo dos saberes psicológicos. Nomes como Raul Briquet, Arthur Ramos, Donald Pierson, Virginia Leone Bicudo, Aniela Ginsberg e Dante Moreira Leite estão entre os principais estudiosos desse campo no período de 1930 até 1950; ao mesmo tempo, também são responsáveis pelos primeiros cursos acadêmicos que tratam de Psicologia social e de delimitação do campo da Psicologia no Brasil.

Raul Briquet ministrou o primeiro curso de Psicologia social, em 1933, na Escola Livre de 
Sociologia e Política de São Paulo. O curso gerou a publicação do livro Psicologia Social, em 1935, no qual destaca os grupos sociais e as questões relativas ao preconceito racial, em um momento em que ao preconceito contra negros eram acrescidas barreiras à imigração japonesa no País. O segundo curso foi ministrado por Arthur Ramos, em 1935, na Escola de Economia e Direito da extinta Universidade do Distrito Federal, no Rio de Janeiro. Do curso, resultou o livro Introdução à Psicologia Social, publicado em 1936. Arthur Ramos já era conhecido por sua obra O Negro Brasileiro, de 1934, e por criticar a visão determinista biológica de raça de seu mestre Nina Rodrigues na explicação da inferioridade dos negros usando um viés culturalista. O terceiro curso de Psicologia social foi ministrado por Donald Pierson, na década de 1940, na Escola Livre de Sociologia e Política de São Paulo. Desde 1939, ele estava no Brasil lecionando Sociologia, Psicologia social e Antropologia social, e, dentre seus trabalhos, já se destacava a obra Negroes in Brazil: a Study of Race Contact at Bahia, fruto de sua tese de doutorado defendida na Escola de Chicago, em 1939. Donald Pierson traz para seu curso de Psicologia social a influência dessa escola americana, conhecida por inaugurar um pensamento sociológico centrado nos problemas sociais e na sua reparação; assim, em seu curso, focaliza os conceitos de indivíduo, grupo, comportamento e comunicação à luz das temáticas da imigração, da desorganização social e das relações étnico-raciais (Bonfim, 2004).

É no âmbito da Escola Livre de Sociologia e Política de São Paulo que também se desenvolve, no início da década de 50, um importante estudo sobre relações étnicoraciais no Brasil, coordenado por Roger Bastide e Florestan Fernandes em São Paulo, no qual a Psicologia é chamada a contribuir através de Virgínia Leone Bicudo e Aniela Ginsberg. O estudo foi solicitado pela UNESCO, que buscava entender aquilo que considerava uma experiência singular e bem sucedida de acomodação de diferenças raciais em um país, e envolvia trabalhos em Pernambuco, Bahia, Amazonas, Rio de Janeiro e São Paulo. Os resultados dos trabalhos realizados em São Paulo por Virginia Leone Bicudo e Aniela Ginsberg são publicados em 1955, no livro Relações Raciais entre Negros e Brancos em São Paulo, de Roger Bastide e Florestan Fernandes (Santos, 2010).

Em 1945, sobre a orientação da Donald Pierson, Virginia Leone Bicudo conclui, na Escola Livre de Sociologia e Política de São Paulo, a primeira dissertação de mestrado sobre relações étnico-raciais defendida em uma instituição universitária brasileira: Estudo de Atitudes Raciais de Pretos e Mulatos em São Paulo. Nesse estudo, ela realiza entrevistas com pais de alunos de escolas públicas residentes em quatro bairros populares de São Paulo e um de classe média e com exmilitantes da Frente Negra Brasileira (FNB), organização criada em 1931 que visava a unir os negros para a luta antirracista. A autora conclui que existe preconceito de cor, que se manifesta à medida que o negro ascende socialmente. A rejeição por causa da cor traumatiza e faz com que o negro adquira consciência de cor, e o aumento dessa consciência eleva o esforço de superação do sentimento de inferioridade e a busca por instrução e posições de maior destaque. Contudo, mesmo ascendendo, há limitações nos contatos sociais devido ao preconceito de cor (Santos, 2010).

Virginia Leone Bicudo articula, em sua dissertação, análise sociológica (estrutura de classes, mobilidade social, valores sociais) com Psicologia social (atitudes sociais), em um momento em que as pesquisas iniciais sobre atitudes raciais (preconceitos e estereótipos) realizadas nos EUA buscavam fazer frente ao evolucionismo social e ao determinismo biológico das raças, investigando as motivações 
psicossociais das hostilidades entre os grupos sociais: étnico-raciais e religiosas, entre outros. Essa interface entre Sociologia e Psicologia social ganha mais evidência no final dos anos 40, sob os ecos do Holocausto, que impulsiona uma agenda de pesquisa em ciências humanas no pós-guerra voltada para o estudo de estereótipos, atitudes e caráter nacional. Assim, para o estudo da UNESCO, Virginia Leone Bicudo decide retomar o tema das atitudes raciais realizando o trabalho Atitudes dos Alunos dos Grupos Escolares em Relação com a Cor dos seus Alunos, no qual analisa as atitudes de rejeição ou de intimidade, e de aproximação, de estudantes, associando-as à cor da pele, bem como a influência da família na constituição dessas preferências (Maio, 2010).

Para o estudo da UNESCO, Aniela Ginsberg realiza o trabalho Pesquisa sobre as Atitudes de um Grupo de Escolares em São Paulo em Relação com as Crianças de Cor. Para aferir as atitudes raciais de escolares, a autora investiga a preferência das crianças em relação a bonecas negras e brancas, analisando as justificativas dessas preferências. Aniela Gisnberg é uma das principais autoras de Psicologia na década de 1950 no Brasil, e lecionava na Escola Livre de Sociologia e Política de São Paulo, na Universidade de Bahia e na Pontifícia Universidade Católica de São Paulo. Ela estuda grupos sob diversos aspectos (raças, idades, sexos) com o objetivo de compará-los. Os processos inter e intraculturais, as relações raciais e a imigração estão no centro de suas investigações. Suas pesquisas tinham a preocupação de detectar as especificidades raciais, culturais e nacionais, procurando entender as diferenças e questionando a universalidade do saber psicológico. Dentre seus trabalhos, é importante destacar Psicologia Diferencial, publicado no livro A Psicologia Moderna, de Otto Klineberg, em 1953, no qual sustenta que as diferenças encontradas nos estudos comparativos entre culturas, povos, raças e sexos se devem mais às variáveis externas do que às variáveis internas dos sujeitos pesquisados, ou seja, são os determinantes do meio que geram as diferenças e as particularidades (Azevedo, 2002).

Em 1950, Dante Moreira Leite publica o artigo Preconceito Racial e Patriotismo em Seis Livros Didáticos, no Boletim 03 de Psicologia, da Faculdade de Filosofia, Letras e Ciências Humanas da USP. Nesse artigo, ele denuncia a falta de fundamento científico do preconceito racial, e mostra que, a partir da compreensão dos processos subjetivos que interferem na percepção, é possível entender porque tal preconceito se mantém. Na percepção do comportamento de uma pessoa, interferem os sentimentos negativos e positivos que se tem em relação a ela. Quando a percepção do outro é deformada por conceitos préexistentes e que servem ao mesmo tempo para reforçá-los, ocorre a permanência do preconceito. Ele serve à manutenção da estabilidade social em sistemas onde existe desigualdade de condições, e justifica o domínio, a opressão e os tratamentos e as oportunidades desiguais (Graciano, 1976; Paiva, 2000).

Virgínia Leone Bicudo, Aniela Ginsberg e Dante Moreira Leite explicam as diferenças entre raças através dos fatores ambientais, e combatem a noção de que existem determinantes genéticos subjacentes a essas diferenças, que são explicáveis pelas condições econômicas e educacionais e pela socialização. Os estudos de Psicologia e de Psicologia diferencial realizados pelos três pesquisadores nas décadas de 40 e 50 são fundamentais para desconstruir a visão determinista biológica das raças que prevalecia na Psicologia até então e para mostrar que é na interação dos indivíduos com os grupos e com a sociedade que as diferenças podem transformar-se em desigualdades. 


\section{Estudos sobre branqueamento e branquitude}

Na década de 1990, o pensamento psicológico sobre as relações étnico-raciais no Brasil ganha novo fôlego com os estudos de Jurandir Freire Costa, Iray Carone, Maria Aparecida Bento e Edith Pizza.

Em Jurandir Freire Costa, encontramos o esboço da noção de branqueamento dentro do pensamento psicológico como aquilo que permitiria sustentar no Brasil uma ideologia racial que não prima pela "ideologia da pureza racial", e cujos efeitos são a diminuição da hostilidade e da aversão ao negro e ao mestiço assim que este passa a se apropriar dos comportamentos sociais dos brancos, a embranquecer seus traços (Costa, 2007). Ele identifica em intelectuais da década de 30, como Oliveira Viana, indícios dessa perspectiva, que, ao mesmo tempo em que proclamava e defendia a inferioridade constitucional ou biológica dos negros, exaltava os efeitos benéficos da assimilação promovida pela miscigenação racial, que impedia o racismo de se posicionar contra os contatos interétnico-raciais.

Para Maria Aparecida Bento, o branqueamento é um processo político e psicológico que nasce do medo das elites brasileiras do crescimento da população negra e mestiça; refere-se à construção de uma identidade branca pela pessoa negra, que incorpora um conjunto de padrões de beleza, de atitudes e de valores visando a assemelhar-se a um modelo branco e a construir uma identidade étnico-racial positiva (Bento, 2002). Por outro lado, se a escravidão, a abolição e a república contribuíram para direcionar os negros para o processo de branqueamento, algo também ocorreu com os brancos. Como os processos psicossociais presentes nas relações de dominação afetaram os brancos e como eles passaram a construir suas identidades?
Com essa pergunta, os estudos sobre raça no Brasil passam a buscar inspiração nos estudos críticos sobre branquitude (critical whiteness studies) realizados nos Estados Unidos. Ocorre uma mudança de foco, que permite que novos olhares sobre o tema possam surgir.

O movimento de mudança nesses estudos se deu quando os olhares acadêmicos da Psicologia social se deslocaram dos outros racializados para o centro sobre o qual foi construída a noção de raça, ou seja, para os brancos. Esse novo enfoque foi chamado de estudos sobre branquitude. Tais estudos, marcados pela transferência do olhar das margens para o centro, correspondem ao mesmo posicionamento dos estudos feministas, que recolocaram a questão do gênero em outros parâmetros. Considerando a categoria gênero como relacional, passaram também a investigar o problema do homem, retirando, assim, a mulher do foco problemático no qual recaíam os estudos sobre as desigualdades de gênero. $\mathrm{Na}$ mesma lógica, a heterossexualidade passou a ser questionada em sua norma e suas práticas, com a finalidade de desmarginalizar a homossexualidade. Em todos esses casos, a lógica foi tirar o olhar das identidades consideradas de margem e voltá-lo para a autoconstrução do centro com o intuito de ver, revelar e denunciar também o conteúdo dessas identidades hegemônicas, que até então haviam sido poupadas de uma análise crítica.

Alinhadas a essa perspectiva, Iray Carone, Maria Aparecida Bento e Edith Pizza inauguram os estudos de branquitude e branqueamento na psicologia social brasileira. O foco deixa de ser a negritude e passa a ser a branquitude, ou seja, a identidade étnico-racial que uma pessoa branca pode escolher ou não revelar: "ser branco é não ter de pensar sobre isso". Trata-se de um modo de comportamento social a partir de uma situação estruturada de poder, baseada em uma racialidade 
Edith Pizza argumenta que, se há algo característico da identidade racial

branca, essa característica é a invisibilidade, que se concretiza diariamente através da falta de percepção do indivíduo branco

como ser racializado. neutra, não nomeada, percebida como não constitutiva da identidade imediata do sujeito, mas sustentada pelos privilégios sociais cotidianamente experimentados (Carone \& Bento, 2002).

Bento estudou as manifestações da racialidade branca, denominada branquitude, nos discursos de gestores de pessoal. E, por meio das entrevistas realizadas, delineou uma série de características da branquitude, quais sejam: (1) há o reconhecimento da existência do racismo e da desigualdade racial no Brasil, porém, não se nota a discriminação vivida pelo negro cotidianamente, (2) há uma tendência para culpabilizar o negro pelas dificuldades vividas por ele, (3) o tema das relações étnico-raciais é constantemente silenciado; dessa formal, a cor da pele do branco é vivida como neutra e como a norma, (4) não se nota os negros nos espaços sociais, ou, no dizer da autora, não se nota a "parte negra do negro", isso porque reconhecer o sujeito negro como negro significa identificá-lo como sujeito discriminado e remeter-se a si próprio como branco e cúmplice ou beneficiário de uma situação moralmente condenável.

Os participantes da pesquisa de Bento reconhecem que existe racismo e desigualdade racial, mas não associam esse fato à discriminação. O fato de ser negado aos negros o acesso aos espaços sociais é visto como um problema deles mesmos ou como uma consequência direta da escravidão; porém, se o passado escravista traz consequências para o negro, isso também é verdade para o branco e para o mestiço, tema em geral silenciado.

Segundo Bento, a branquitude é uma determinada forma de viver o mundo, garantida pelos benefícios simbólicos decorrentes do privilégio em que a hierarquia racial coloca e mantém os brancos. Desse modo, o silêncio e a omissão desse grupo são uma forma de manter a desigualdade racial. A autora chama isso de pacto narcísico, isto é, um pacto entre pessoas do mesmo grupo, no caso, os brancos, em não falar de racismo, não apontar os privilégios que o racismo deixa para os brancos, e não responsabilizar o branco pelo passado e pelo presente de discriminação.

Edith Pizza argumenta que, se há algo característico da identidade racial branca, essa característica é a invisibilidade, que se concretiza diariamente através da falta de percepção do indivíduo branco como ser racializado. A brancura, nesse caso, é vista pelos próprios sujeitos brancos como algo natural e normal. Edith Pizza classifica essa identidade coletiva como uma construção em contraposição, em que os não brancos são aqueles que têm a visibilidade da raça. Assim, para a autora, a branquitude só existe em relação.

Não se trata, portanto, da invisibilidade da cor, mas da intensa visibilidade da cor e de outros traços fenotípicos aliados a estereótipos sociais e morais para uns, e a neutralidade racial para outros. As consequências dessa visibilidade para os negros são bem conhecidas, mas a da neutralidade do branco é dada como 'natural', já que ele é o modelo paradigmático de aparência e de condição humana (Pizza, 2002, p. 72)

Schucman (2012) questiona essa invisibilidade no Brasil, amparada na socióloga norteamericana Ruth Frankenberg (2004), para quem a identidade racial branca não é invisível, mas vista por uns e não por outros; dependendo dos interesses, ela pode ser anunciada ou permanecer invisível. Como exemplo, podemos citar a discussão sobre as cotas raciais na universidade pública. Nessa discussão, os brancos, em sua maioria, são capazes de perceber e de reconhecer sua branquitude a ponto de se posicionarem contra, dizendo que as cotas os excluem. Para Frankenberg, a invisibilidade acontece 
somente quando uma sociedade incorpora uma ideia de supremacia racial branca tão poderosa na qual os não brancos não têm voz nem poder para apontar a hegemonia dessa identidade racial, e os brancos, por sua vez, não conseguem se perceber como mais uma das identidades raciais, e sim, como a identidade racial normal, que deve ser alcançada pelas outras nos níveis intelectuais, morais, estéticos, econômicos.

Os estudos sobre branqueamento e branquitude realizados pela Psicologia a partir da década de 90, ao tomarem a raça como uma construção social, evidenciam as relações de poder que essa estrutura leva: ao privilégio simbólico e material dos sujeitos brancos e aos aviltamentos relacionados aos negros em nossa sociedade. Eles mostram que, assim como as categorias de classe e de gênero, a categoria raça constitui, diferencia, hierarquiza e localiza os sujeitos em nossa sociedade.

\section{Considerações finais}

Neste texto, buscamos traçar uma linha no tempo do pensamento psicológico acerca das relações étnico-raciais no Brasil. Compreende-se que, inicialmente, os trabalhos de Raimundo Nina Rodrigues garantiram a consolidação de um modelo psicofísico de explicação sobre as deficiências do negro brasileiro e as consequências sociais da manutenção do convívio com essa raça. Em seguida, ocorreu uma virada nessa discussão, com Virgínia Leone Bicudo, Aniela Ginsberg e Dante Moreira Leite, que passaram a explicar as diferenças entre raças através dos fatores ambientais (condições econômicas, educacionais e sociais), com o intuito de desconstruir a ideia da existência de determinantes genéticos que pudessem causar essas diferenças. Por fim, tomando a raça como uma construção social, Jurandir Freire Costa, Maria Aparecida Bento e Edith Pizza focalizaram as relações de poder, evidenciando a força dessa categoria como fator de diferenciação e de hierarquização social.

Utilizando a perspectiva histórica como recurso analítico, foi possível identificar esses três momentos na construção do pensamento psicológico sobre as relações étnico-raciais, definidos aqui como momentos: biológicocausal, culturalista e relacional. Trata-se de momentos de ruptura e de configuração de novos saberes em Psicologia sobre essa temática do ponto de vista da compreensão das experiências de alteridade, de poder e de intersubjetividade.

A construção da linha do tempo foi uma tentativa de trazer para o campo da Psicologia uma outra perspectiva de discussão da temática étnico-racial, repensando o papel dos modelos e das teorias psicológicas nesse debate.

Os estudos na área devem considerar que o momento atual sugere maior ênfase no aspecto relacional da construção das identidades. Seria conveniente, portanto, investigar as relações étnico-raciais entre negros, brancos, amarelos, indigenas, enfim, entre todas as raças-etnias do País.

Defendemos também a realização de novos estudos que permitam o aprofundamento das especificidades históricas, sociais e políticas de cada um desses momentos, bem como a sistematização do debate travado acerca da problemática racial e das ideias e dos argumentos dos principais autores envolvidos. Acreditamos que investigar a história da constituição do pensamento psicológico sobre as relações étnico-raciais em finais do século XIX e suas transformações ao longo do século XX possibilitará refletir sobre a própria gênese da Psicologia e sua atualidade na produção de visões de mundo e de ser humano. 


\section{Alessandro de Oliveira dos Santos}

Doutor. Professor do Departamento de Psicologia Social e do Trabalho do Instituto de Psicologia da Universidade de São Paulo - SP - Brasil.

E-mail: alos@usp.br

\section{Lia Vainer Schucman}

Doutora em Psicologia Social pela Universidade de São Paulo, São Paulo - SP - Brasil.

E-mail: liavainers@gmail.com

\section{Hildeberto Vieira Martins}

Doutor. Professor do Departamento de Psicologia Social da Universidade Federal Fluminense,

Rio de Janeiro - RJ - Brasil.

E-mail: betohvm@vm.uff.br

\section{Endereço para envio de correspondência:}

Av. Professor Mello Moraes, 1721 Cidade Universitária, São Paulo - SP - Brasil. CEP: 05508-030

\section{Referências}

Antunes, M. A. M. (1998). A psicologia no Brasil - leitura histórica sobre sua constituição. São Paulo: Unimarco Editora/EDUC.

Azevedo, M. L. B. (2002). A obra de Aniela Ginsberg: uma contribuição para a história da psicologia social no Brasil. Tese de doutorado em Psicologia Social, PUC/SP.

Benjamin, W. (1987). Obras escolhidas I: magia, técnica e política. São Paulo: Brasiliense.

Bento, M. A. S. (2002). Pactos Narcíssicos no Racismo: Branquitude e poder nas organizações empresáriais e no poder público. Tese de Doutorado em Psicologia, Universidade de São Paulo, SP.

Bicudo, V. L. (1945). Estudo de atitudes raciais de pretos e mulatos em São Paulo. Dissertação de mestrado em Ciência, Escola Livre de Sociologia e Política de São Paulo, SP.

Bonfim, E. M. (2004). Históricos dos cursos de psicologia social no Brasil. Psicologia \& Sociedade, 16(2), 32-36.

Carone, I., \& Bento, M. A. S. (2002). Psicologia social do racismo: estudos sobre branquitude e branqueamento no Brasil. Petrópolis, RJ: Vozes.

Chaves, E. S. (2003). Nina Rodrigues: sua interpretação do evolucionismo social e da psicologia das massas nos primórdios da psicologia social brasileira. Psicologia em Estudo, 8(2), 29-37.

Costa, J. F. (2007). História da psiquiatria no Brasil: um corte ideológico. São Paulo: Garamond.

Frankenberg, R. (2004). A miragem de uma branquidade não marcada. Rio de Janeiro: Garamond.

Frochtengarten, F. (2005). A memória oral no mundo contemporâneo. Estudos Avançados, 19(55), 367-376.
Graciano, M.(1976). Dante Moreira Leite face a preconceitos e ideologias sobre caráter nacional. Cadernos de Pesquisa, 17, 9-12.

Maio, M. C. (2010). Educação sanitária, estudos de atitudes raciais e psicanálise na trajetória de Virgínia Leone Bicudo. Cadernos Pagu, 35, 309-355.

Martins, H. V. (2009). As ilusões da cor: sobre raça e assujeitamento no Brasil. Tese de doutorado em Psicologia Social, Instituto de Psicologia da Universidade de São Paulo, SP.

Massimi, M. (2007). O processo de institucionalização do saber psicológico no Brasil do século XIX. In A. M. Jacó-Vilela, A. A. L. Ferreira, F. T. Portugal (Orgs.), História da psicologia: rumos e percursos (pp. 159-168). Rio de Janeiro: Nau.

Paiva, G. J. (2000). Dante Moreira Leite: um pioneiro da psicologia social no Brasil. Psicologia USP, 11(2), 25-57.

Pizza, E. (2002). Porta de vidro. Entrada para a branquitude. In I. Carone; \& M. A. S. Bento. (orgs.), A Psicologia social do racismo: estudos sobre branquitude e braqueamento no Brasil. (p. 72). Petrópolis, RJ: Vozes.

Santos, A. O. (2010). A psicologia social brasileira na compreensão das diferenças: décadas de 1930, 1940 e 1950 (10 p., mimeo). Núcleo de Pesquisa: História da Psicologia, Programa de PósGraduação em Psicologia Social da Pontifícia Universidade Católica de São Paulo, SP

Schucman, L. V. (2012). Entre o "encardido", o "branco" e o "branquíssimo": raça, hierarquia e poder na construção da branquitude paulistana. Tese de doutorado, Instituto de Psicologia, Universidade de São Paulo, São Paulo, SP.

Schwarcz, L. M. (1995). O espetáculo das raças: cientistas, instituições e questão racial no Brasil. São Paulo: Companhia das Letras. 